\title{
Avaliação da água para consumo humano nas comunidades rurais do Campo Petrolífero Canto do Amaro-CPCA, RN, Brasil
}

\section{Evaluation of drinking water in rural communities of the Oilfield Canto do Amaro-CPCA, RN, Brazil}

Jorge Luís de Oliveira Pinto Filho ${ }^{\mathrm{a}}$

Raquel Franco de Souza ${ }^{b}$

Reinaldo Antônio Pettac

aProfessor Adjunto I da Universidade Federal Rural do Semiárido. Pau dos Ferros, RN, Brasil. End. Eletrônico: jorge.filho@ufersa.edu.br

${ }^{b}$ Professora Titular do Departamento de Geologia da Universidade Federal do Rio Grande do Norte, Natal, RN, Brasil. End. Eletrônico: francodesouza.raquel@gmail.com

'Professor Titular do Departamento de Geologia da Universidade Federal do Rio Grande do Norte, Natal, RN, Brasil. End. Eletrônico: petta@ccet.ufrn.br

doi:10.18472/SustDeb.v9n2.2018.27829

\section{RESUMO}

Objetivou-se avaliar o sistema de abastecimento e a qualidade da água para consumo humano das comunidades rurais do Campo Petrolífero Canto do Amaro - CPCA, RN. A metodologia constou de identificação do sistema de abastecimento, avaliação do abastecimento a partir da percepção ambiental e análises físico-químicas e de metais pesados na água. Constatou-se que Turbidez, pH, Condutividade Elétrica, Dureza, Amônia, Nitrato, Nitrito, Cálcio, Magnésio e Ferro apresentaram valores aceitáveis conforme a Portaria do Ministério da Saúde n 2.914/2011 e a Resolução Conama n 357/2005. Para o Oxigênio Dissolvido observou-se que $84,61 \%$ das amostras apresentaram valores abaixo do permitido pela Resolução Conama n³57/2005. Evidenciou-se também que o Teor de Óleo e Graxas (TOG) nas amostras variou entre 0,36 a $6,10 \mathrm{mg} / \mathrm{L}$, com teor médio de $1,42 \mathrm{mg} / \mathrm{L}$, sendo um indicativo de potencial risco à saúde humana, já que para a Resolução Conama n³57/2005, TOG devem ser virtualmente ausentes. Os valores de $\mathrm{Cd}, \mathrm{Cu}, \mathrm{Cr}$ e $\mathrm{Pb}$ foram todos abaixo dos limites de detecção do método utilizado para análise. As concentrações de Zn variam entre 0,01 e 0,04 mg/L, com média de 0,01 mg/L, dentro dos valores máximos estabelecidos pela Resolução Conama n³57/2005 e a Portaria no 2.914/2011.

Palavras-chave: Abastecimento de Água; Consumo Doméstico de Água; Saúde Ambiental. 


\section{ABSTRACT}

This work aimed to evaluate the supply system and water quality for human consumption of rural communities of the Oilfield Canto do Amaro (CPCA), in the state of Rio Grande do Norte (RN). The methodology consisted in identifying the supply system, evaluation of supply through environmental perception, and analysis of the physicochemical parameters and heavy metals in water. It was found that turbidity, $\mathrm{pH}$, electrical conductivity, hardness, ammonia, nitrate, nitrite, calcium, magnesium and iron presented acceptable values determined by the Directive No. 2914/2011 of the Ministry of Health and Resolution No. 357/2005 of the National Council for Environment (CONAMA). As for the dissolved oxygen, it was observed that $84.61 \%$ of the samples had lower levels than allowed by CONAMA Resolution No. 357/2005. It was evident also that the oil and grease content in the samples ranged from 0.36 to $6.10 \mathrm{mg} / \mathrm{L}$, with an average content of $1.42 \mathrm{mg} / \mathrm{L}$, with a potential indicative of risks to human health. According to CONAMA Resolution No. 357/2005 oil and greases should be virtually absent. The amounts of $\mathrm{Cd}, \mathrm{Cu}, \mathrm{Pb}$ and $\mathrm{Cr}$ were all below the Limit of Detection (LOD) of the method used for analysis. Zinc concentrations ranged between 0.01 and $0.04 \mathrm{mg} / \mathrm{L}$, with a mean of $0.01 \mathrm{mg} / \mathrm{L}$, within the maximum amounts established by CONAMA Resolution No. 357/2005 and Directive No. 2914/2011.

Keywords: Water Supply; Domestic Water Consumption; Environmental Health.

\section{INTRODUÇÃO}

A água é um importante recurso natural e se encontra presente na maioria dos processos metabólicos, constituindo um elemento de vital importância para a sobrevivência dos seres vivos. Conforme sua qualidade, pode ser utilizada para diversos fins, tais como: consumo humano, atividades agrícolas e pecuárias, geração de energia elétrica, transporte hidroviário, uso industrial, pesca e aquicultura, turismo e lazer (DERÍSIO, 2012). Esses usos múltiplos podem resultar nas alterações das características físico-químicas e biológicas da água por meio de processos de poluição e/ou contaminação, ocasionando consequências de ordem social, econômica, política, ambiental, ecológica e de saúde.

Na região oeste do estado do Rio Grande do Norte localiza-se a Bacia Hidrográfica do Rio ApodiMossoró/RN - BHRAM/RN, que ocupa uma área de $14.276 \mathrm{~km}^{2}$ (26,8\% do território estadual), sendo composta por quatro unidades: alto curso, médio curso superior, médio curso inferior e baixo curso (SEMARH, 2015).

O baixo curso da BHRAM/RN encontra-se situado em uma região estuarina de potencial econômico, o que possibilitou o estabelecimento de comunidades e o desenvolvimento de atividades produtivas, relacionadas com a exploração de petróleo e gás, mineração de areia e calcário, salinas, comércio e serviços, urbanização, tráfego de veículos, transporte de cargas, construção civil, turismo e hotelaria, fruticultura irrigada, carcinicultura, pesca, pecuária e energia eólica.

Ainda no baixo curso dessa bacia encontra-se o Campo Petrolífero Canto do Amaro - CPCA, região de maior produção nacional de petróleo em terra (PORTAL BRASIL, 2014) com sua respectiva infraestrutura de exploração, perfuração e produção. Apesar dessa dinâmica econômica, essa área encontra-se em situação de vulnerabilidade socioambiental pela geração de emissões atmosféricas, resíduos sólidos e semissólidos, efluentes líquidos e ruídos; processos de poluição hídrica, terrestre, sonora, atmosférica e visual; supressão vegetal; processos erosivos; interferência na biota; riscos à saúde dos trabalhadores e pressão nas comunidades e serviços públicos (PINTO FILHO; PETTA, 2016; PINTO FILHO; PETTA; SOUZA, 2016). Ainda conforme os autores, é perceptível a interferência no meio antrópico por meio de impactos socioeconômicos negativos nas comunidades locais.

Essa bacia hidrográfica foi objeto de diferentes estudos, como o de Araújo, Santos e Araújo (2007), que realizaram o monitoramento das águas do Rio Apodi-Mossoró; o de Lemos, Ferreira Neto e Dias (2009), que avaliaram a qualidade da água na Lagoa do Apodi, RN; o de Bezerra et al. (2013), que analisaram a qualidade da água em trecho urbano no respectivo rio; e Silva e Souza (2013), que investigaram os efeitos antrópicos na qualidade da água do Rio do Carmo. Entretanto, esses artigos não estavam voltados para a análise da qualidade da água para o consumo humano. 
Outras realidades sobre o estudo da água também foram abordadas por Obiefuna e Sheriff (2011) sobre a qualidade das águas subterrâneas na Nigéria; Siqueira, Aprile e Migueis (2012) referente à qualidade da água do Rio Parauapebas, PA; Stein et al. (2012) alusivo à qualidade das águas do aquífero Barreiras no setor sul de Natal e norte de Parnamirim, RN; Zan et al. (2012) relativo à qualidade das águas superficiais do Rio Jamari, Monte Negro, RO; Landim Neto et al. (2013) pertinente à qualidade da água subterrânea em Aquiraz, CE; e Santi et al. (2013) concernente à qualidade da água do Igarapé São Francisco, Rio Branco, AC.

Estudos da qualidade da água vêm sendo realizados com diferentes abordagens. Citam-se trabalhos realizados dos riscos de sistemas de tratamento de água (WRIGHT et al., 2004; VARGHESE, 2004) e da contaminação hídrica através das condições sanitárias (SCORSAFAVA et al., 2010). As características físico-químicas e biológicas da água também vêm sendo estudadas por Feitosa (2000); Libânio (2005); Mierzwa e Hespanhol (2005); Von Sperling (2005); Companhia Ambiental do Estado de São Paulo (CETESB, 2010); Esteves (2011); Derísio (2012); Perpétuo (2014) e Instituto Mineiro de Gestão das Águas (IGAM, 2015).

Questões relacionadas ao abastecimento de água, cada vez mais, têm gerado preocupação por parte de especialistas e gestores, já que a dificuldade de acesso e a qualidade da água são considerados fatores de risco para a saúde, comprometendo o desenvolvimento da população. Com isso, a relação da qualidade da água e saúde humana vem sendo investigada por Heller (1997), Giatti (2007), Razzolini e Gunther (2008), Queiroz, Heller e Silva (2009), Rodrigues et al. (2012), Prosenewicz e Lippi (2012), Bevilacqua et al. (2014) e Souza et al. (2016).

Diante dessa situação, verifica-se a relevância de avaliar o sistema de abastecimento de água para consumo humano nas comunidades rurais da área do CPCA/RN, que são constituídas por agricultores familiares, por meio da percepção ambiental e do monitoramento da água. Ressalta-se o interesse em investigar essa área de estudo pelo fato de ser uma região rural no semiárido brasileiro próxima de intervenção antrópica, o que resulta em um cenário de deficiências nas condições de saneamento ambiental, restrições climáticas e pressão industrial.

O monitoramento vai além de verificar se os padrões legais de qualidade da água estão sendo obedecidos ou não, com isso busca responder o que está sendo alterado e o porquê dessas modificações (TUCCl, 2006). Para isso, a percepção ambiental pode ser utilizada em estudos sobre qualidade da água, já que é considerada um instrumento que compreende melhor as inter-relações entre o homem e o ambiente (MELAZO, 2005).

Somado aos dados de percepção ambiental, deve-se existir o monitoramento de água, que contribui para reduzir a pressão da degradação antropogênica sobre os ecossistemas aquáticos por meio do auxílio no planejamento de medidas de mitigação da degradação ecológica (MAROTTA; SANTOS; ENRICH-PRAST, 2008). A não disponibilidade de dados de qualidade da água é um dos principais problemas dos países em desenvolvimento (BHATTI; LATIF, 2011), justificando dessa forma seu monitoramento.

O objetivo deste estudo é avaliar água para fins de consumo das comunidades rurais do CPCA/RN. Para isso, elencaram-se como objetivos específicos: a) identificar a forma de abastecimento hídrico para a população na região; b) apontar fragilidades do sistema de abastecimento a partir da percepção ambiental da população e c) analisar a qualidade físico-química e a presença de metais pesados na água para consumo humano.

\section{MATERIAL E MÉTODOS}

\subsection{DELIMITAÇÃO E CARACTERIZAÇÃO DA ÁREA DE ESTUDO}

No baixo curso da BHRAM/RN localiza-se o CPCA/RN, que vem sendo explorado desde 1986, com uma reserva de 116 milhões de barris de óleo (MILANI; ARAÚJO, 2003). Esse campo é a maior região de produção nacional de petróleo em terra, a partir do ano de 2014 vem operando com 1.109 poços de 
petróleo e/ou gás (PORTAL BRASIL, 2014) em uma infraestrutura de exploração, perfuração e produção de petróleo e gás situada em comunidades rurais dos municípios de Mossoró e Areia Branca.

No município de Mossoró estão as comunidades Piquiri I (24 M 701770 9438229), Piquiri II (24 M 701253 9437594), Sussuarana (24 M 696822 9429181), Alto da Pedra (24 M 696816 9428695), Carmo (24 M 690260 9429625) e Melancias (24 M 693166 9423051); as comunidades no município de Areia Branca são Serra Vermelha (24 M 706325 9442560), Garavelo I, II, III e IV (24 M 709766 9445462), Freire (24 M 710264 9446048), Reforma I, II e III (24 M 712798 9446908) e Canto do Amaro (24 M 704652 9440754) (Figura 1). Ressalta-se que essas comunidades apresentam deficiências nos componentes de saneamento ambiental, principalmente relacionadas a: limitação no abastecimento de água, sendo consumida com tratamento prévio sem orientação; inexistência de esgotamento sanitário, onde parcela da população despeja os efluentes para fossa, solo e plantas; e gestão dos resíduos sólidos irregular (PINTO FILHO; PETTA; SOUZA, 2016).

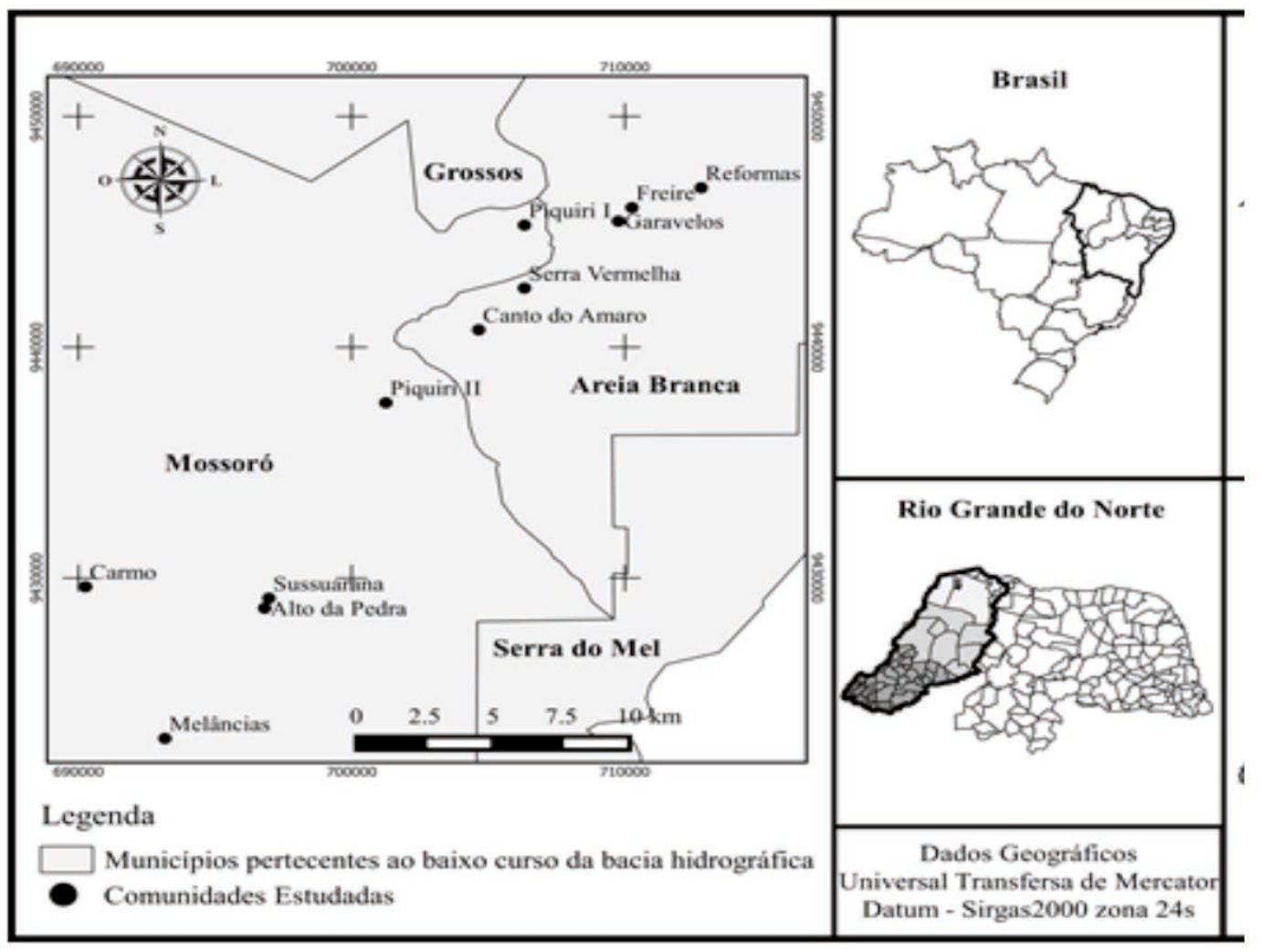

Figura 1 - Localização da área de estudo.

Fonte: Pinto Filho (2018).

\subsection{PROCEDIMENTOS TEÓRICOS E METODOLÓGICOS DA PERCEPÇÃO AMBIENTAL}

A pesquisa classifica-se conforme sua finalidade em descritiva (descreve as características de dada população ou fenômeno em estudo) e exploratória (torna o problema mais explícito). Quanto aos meios utilizados, enquadra-se como bibliográfica e de campo (GIL, 2006).

Nessa perspectiva, de descrever a população e investigar a problemática da área de estudo, utilizou-se estudo de percepção ambiental, já que é considerada uma ferramenta de sustentabilidade por meio da reaproximação do homem com a natureza, permitindo dessa forma compreender as condições do sistema de abastecimento de água para consumo humano das comunidades rurais ao entorno do $\mathrm{CPCA} / \mathrm{RN}$, bem como identificar o reflexo dessas condições na qualidade de vida de tais comunidades, mediante os procedimentos: a) definição do instrumento de percepção ambiental; b) processo de 
amostragem; c) pesquisa de campo; d) tratamento de dados. Ressalta-se ainda que a percepção da comunidade local é considerada indicador de efetividade de gestão, já que se permite acompanhar os serviços na vida dos moradores (RODRIGUES et al., 2012).

\section{a) Instrumento de Percepção Ambiental}

Adotou-se como instrumento de percepção ambiental um questionário semiestruturado abordando aspectos dos tipos de usos da água para consumo humano: beber, limpeza de frutos e legumes, e limpeza de utensílios de manipulação de alimentos; avaliação da qualidade e quantidade da água do abastecimento; os principais problemas do abastecimento e as doenças de maior ocorrência na região investigada para possivelmente correlacionar com vetores de doenças hídricas.

\section{b) Processo de Amostragem}

No processo de amostragem, o procedimento se deu por meio de sorteio, do total de 750 residências, usando como fonte de dados Unidade Básica de Saúde - UBS (2013) das comunidades rurais pertencentes à região do CPCA/RN.

O cálculo do tamanho da amostra para uma população de 750 residências, com margem de erro de 5\%, confiança de $95 \%$ e variabilidade máxima, foi realizado segundo Bolfarine e Bussab (2005), definindose a aplicação de 254 questionários, distribuídos de forma proporcional entre as comunidades (Tabela 01).

Tabela 01 - Distribuição das famílias questionadas por comunidades rurais do CPCA/RN, 2013.

\begin{tabular}{|c|c|c|c|}
\hline COMUNIDADES & MUNICIPIOS & DOMICILIOS & AMOSTRAGEM \\
\hline Serra Vermelha & Areia Branca & 100 & 34 \\
\hline Garavelo I, II, III e IV & Areia Branca & 20 & 7 \\
\hline Freire & Areia Branca & 30 & 10 \\
\hline Reforma I, II e III & Areia Branca & 100 & 34 \\
\hline Canto do Amaro & Areia Branca & 70 & 24 \\
\hline Piquiri I & Mossoró & 80 & 27 \\
\hline Piquiri II & Mossoró & 80 & 27 \\
\hline Sussuarana & Mossoró & 110 & 36 \\
\hline Alto de Pedra & Mossoró & 80 & 27 \\
\hline Carmo & Mossoró & 40 & 14 \\
\hline Melancias & Mossoró & 40 & 14 \\
\hline \multicolumn{2}{|c|}{ TOTAL } & 750 & 254 \\
\hline
\end{tabular}

Fonte: Pinto Filho (2018).

\section{c) Pesquisa de Campo}

No período entre fevereiro e março de 2014 ocorreu o survey, com aplicação dos questionários nas comunidades de Areia Branca e de Mossoró, onde foi disponibilizado aos atores participantes o Termo de Consentimento Livre de Esclarecimento - TCLE, constando os esclarecimentos da pesquisa e os contatos dos pesquisadores. Além disso, foram mencionados os critérios de inclusão e exclusão dos participantes e os riscos da pesquisa. A escolha pelo método de survey deve-se ao fato de permitir enunciados descritivos, explicativos e exploratórios sobre uma população, isto é, descobrir a distribuição de certos atributos dessa população (BABBIE, 2001).

\section{d) Tratamento de Dados}

Ao final da realização da pesquisa de campo, os dados foram checados e inseridos no banco de dados no Statistical Package for Social Sciences (SPSS) versão 16.0, software estatístico utilizado para montagem, processamento e análise descritiva. 


\subsection{PROCEDIMENTOS METODOLÓGICOS DA ANÁLISE DE ÁGUA}

Quanto à amostragem, foram coletadas amostras de água de 25 domicílios, sendo esse valor definido a partir de Bolfarine e Bussab (2005) que ponderam que uma amostra igual ou superior a 25 será sempre considerada normal, ou seja, significativa, com isso estabeleceu-se uma amostragem não probabilística onde esse número representa $10 \%$ do total de moradores entrevistados.

As amostras de água foram coletadas na área nos dias 21 e 27/03/2014 utilizando metodologia da American Public Health Association - APHA (1995). Os locais foram georreferenciados com GPS de navegação Garmin e distribuídos proporcionalmente por comunidades do CPCA/RN (Tabela 02). As amostras foram obtidas nos reservatórios das residências (cisternas, poços, caixas-d'água de PVC e torneiras).

Tabela 02 - Sistema de abastecimento de água por comunidades rurais do CPCA/RN, 2014.

\begin{tabular}{cccccc}
\multirow{2}{*}{ PONTOS } & COORDENADAS & HORARIO & COMUNIDADES & $\begin{array}{c}\text { SISTEMA DE } \\
\text { ABASTECIMENTO }\end{array}$ \\
\cline { 2 - 3 } 01 & $\mathbf{X}$ & $\mathbf{Y}$ & & & \\
02 & 706327 & 9442560 & $9: 16$ & Serra Vermelha & \\
03 & 709766 & 9443507 & $9: 24$ & Serra Vermelha & \\
04 & 710264 & 9446048 & $9: 59$ & Garavelo & Freire \\
05 & 704652 & 9440754 & $10: 55$ & Canto do Amaro & \\
06 & 703517 & 9439887 & $11: 11$ & Canto do Amaro & Carro-pipa \\
07 & 712798 & 9446908 & $11: 33$ & Reforma & \\
08 & 706327 & 9442560 & $11: 57$ & Reforma & \\
09 & 716358 & 9443123 & $12: 15$ & Reforma & \\
10 & 711362 & 9436435 & $13: 03$ & Reforma & \\
11 & 716031 & 9437745 & $13: 31$ & Reforma & \\
12 & 715704 & 9442421 & $13: 42$ & Reforma & \\
13 & 706327 & 9445290 & $11: 03$ & Piquiri I & \\
14 & 701770 & 9438229 & $11: 21$ & Piquiri I & \\
15 & 701253 & 9437594 & $11: 31$ & Piquiri II & \\
16 & 701180 & 9437637 & $11: 42$ & Piquiri II & \\
17 & 696972 & 9429126 & $11: 59$ & Sussuarana & \\
18 & 696822 & 9429181 & $12: 10$ & Sussuarana & \\
19 & 6967730 & 9428853 & $12: 13$ & Sussuarana & \\
20 & 695669 & 9424544 & $14: 08$ & Sussuarana & \\
21 & 693166 & 9423051 & $15: 53$ & Melancia & \\
22 & 690239 & 9429646 & $16: 24$ & Melancia & \\
23 & 690260 & 9429625 & $16: 34$ & Carmo & \\
24 & 696816 & 9428695 & $12: 21$ & Alto da Pedra & \\
25 & 690569 & 9430412 & $17: 00$ & Alto da Pedra & \\
\hline
\end{tabular}

Fonte: Pinto Filho (2018).

A caracterização físico-química da água desse ambiente levou em consideração os seguintes parâmetros: Turbidez, pH, Condutividade Elétrica, Dureza Total, Amônia, Nitrito, Nitrato, Cálcio, Magnésio, Ferro, Oxigênio Dissolvido e Teor de Óleo e Graxas. Os elementos $\mathrm{Ca}, \mathrm{Ba}, \mathrm{Cu}, \mathrm{Mn}, \mathrm{Na}, \mathrm{Pb}, \mathrm{Zn}, \mathrm{Cd}, \mathrm{Hg}, \mathrm{Cr}, \mathrm{Ni}$, $\mathrm{U}$ e $\mathrm{V}$ são os mais comuns resultantes de influência industrial (HORTELLANI et al., 2008). No presente trabalho foram analisados os metais $\mathrm{Cd}, \mathrm{Cr}, \mathrm{Cu}, \mathrm{Pb}$ e $\mathrm{Zn}$.

As amostras foram encaminhadas para realização das análises em laboratório comercial, obedecendo aos procedimentos da APHA (1995). Os metais pesados foram analisados por Espectrofotometria de Absorção Atômica - EAA, empregandose o sistema chama ar-acetileno, com limite de detecção de 0,01 mg L-1 (Tabela 03). 
Tabela 03 - Parâmetros, unidades, técnica analítica e limite de detecção do método utilizado.

\begin{tabular}{c|c|c|c}
\hline PARAMETRO & UNIDADE & TECNICA ANALITICA & LIMITE DE DETECÇAO \\
\hline Condutividade & $\mu \mathrm{S} / \mathrm{cm}$ & Potenciometria & - \\
\hline Dureza & $\mathrm{mg} / \mathrm{L}$ & Método volumétrico & 1,00 \\
\hline Cálcio & $\mathrm{mg} / \mathrm{L}$ & Método volumétrico & 0,24 \\
\hline Magnésio & $\mathrm{mg} / \mathrm{L}$ & Método volumétrico & 0,24 \\
\hline Nitrato & $\mathrm{mg} / \mathrm{L}$ & Método colorimétrico & 0,24 \\
\hline Nitrito & $\mathrm{mg} / \mathrm{L}$ & Método colorimétrico & 0,02 \\
\hline Amônia Total & $\mathrm{mg} / \mathrm{L}$ & $\begin{array}{c}\text { Método colorimétrico do } \\
\text { reagente Nessler }\end{array}$ & 0,24 \\
\hline pH & Adimensional & Potenciometria & - \\
\hline Oxigênio Dissolvido & $\mathrm{mg} / \mathrm{L}$ & Método volumétrico & - \\
\hline Turbidez & $\mathrm{UT}$ & Método colorimétrico & 5,00 \\
\hline Ferro Total & $\mathrm{mg} / \mathrm{L}$ & Método colorimétrico & 0,04 \\
\hline Metais Pesados & $\mathrm{mg} / \mathrm{L}$ & EAA & 0,01 \\
\hline Öleos e Graxas & $\mathrm{mg} / \mathrm{L}$ & Método gravimétrico & 0,40 \\
\hline
\end{tabular}

${ }^{1}$ Fonte: Standard Methods (1995).

Os dados foram submetidos à análise estatística, com o programa Microsoft Office Excel versão 2007 e comparados com os valores da Resolução do Conselho Nacional de Meio Ambiente - Conama $\mathrm{n}^{\circ}$ 357/2005 e da Portaria do Ministério da Saúde n².914/2011.

\section{RESULTADOS E DISCUSSÃO}

\subsection{ABASTECIMENTO HUMANO DE ÁGUA NAS COMUNIDADES DO CPCA/RN}

O sistema de abastecimento de água das comunidades do CPCA/RN ocorre de forma heterogênea, por meio de poço em Mossoró (Figura 02.a) e carros-pipa em Areia Branca (Figura 02.b), com limitações na oferta desse recurso. Resultados similares sobre infraestrutura do abastecimento foram encontrados por Giatti (2007) e Souza et al. (2016) ao analisarem as dificuldades de acesso à água.

02. a

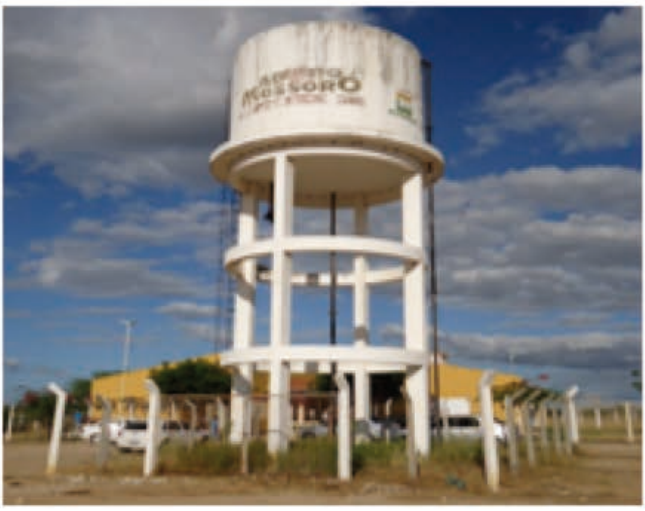

02. $b$

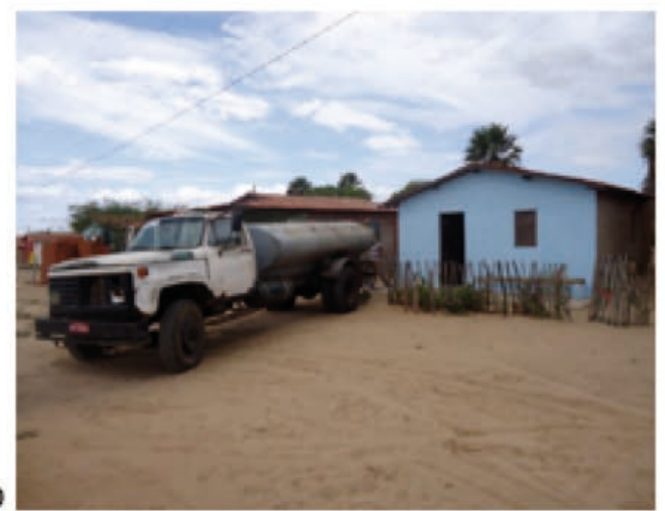

Figura 02 - Abastecimento humano das comunidades rurais no CPCA, 2014. (a) Reservatório em Alto da Pedra em Mossoró. (b) Carro-pipa na comunidade Reforma em Areia Branca. 
Observou-se nas comunidades investigadas de Mossoró que a água é frequentemente armazenada em depósitos com a finalidade de separar do óleo em virtude das diferenças de densidades (Figura 03.a) e tornar-se adequada para consumo. Nas localidades de Areia Branca constataram-se irregularidades na forma de armazenamento (Figura 03.b), tornando um cenário para proliferação de vetores de doenças. Em estudos de Souza et al. (2016) também foram identificadas anormalidades no uso da água de Igarapé-Açu, Pará, relacionadas com a captação, o transporte e o armazenamento de água.

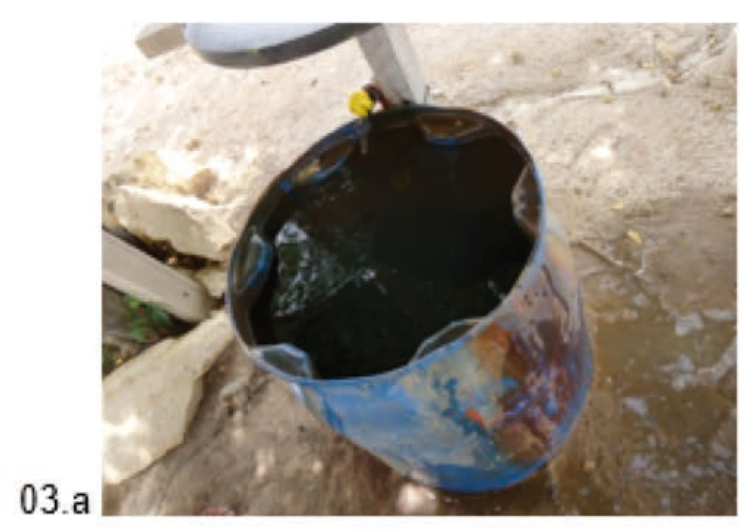

03.b

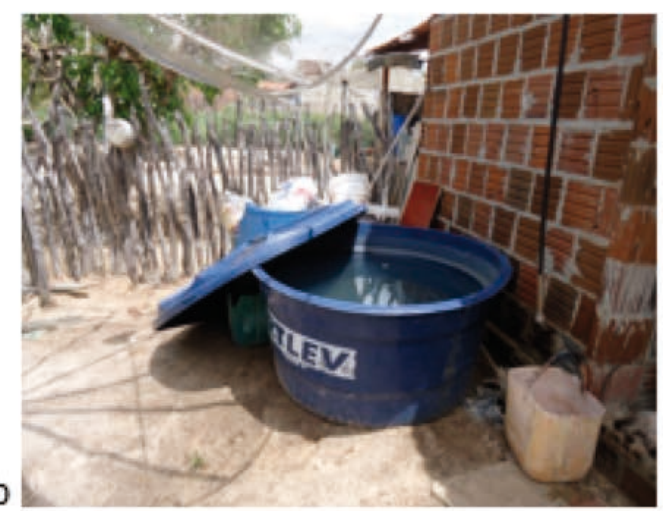

Figura 03 - Armazenamento de água nas comunidades rurais no CPCA, 2014. (a) Balde com água na comunidade Piquiri I em Mossoró. (b) Caixa de PVC com água na comunidade Freire em Areia Branca.

Fonte: Pinto Filho (2018).

A água das comunidades rurais do CPCA/RN vem sendo utilizada para diversos fins, como para uso doméstico (Figura 04.a) na zona rural de Mossoró e para irrigações a partir de cisternas com calçadas de concreto para captação de águas (Figura 04.b) no meio rural de Areia Branca. Diversas estratégias vêm sendo usadas em locais que a água não está bem distribuída com o objetivo de ter o melhor abastecimento (SOUZA et al., 2016).
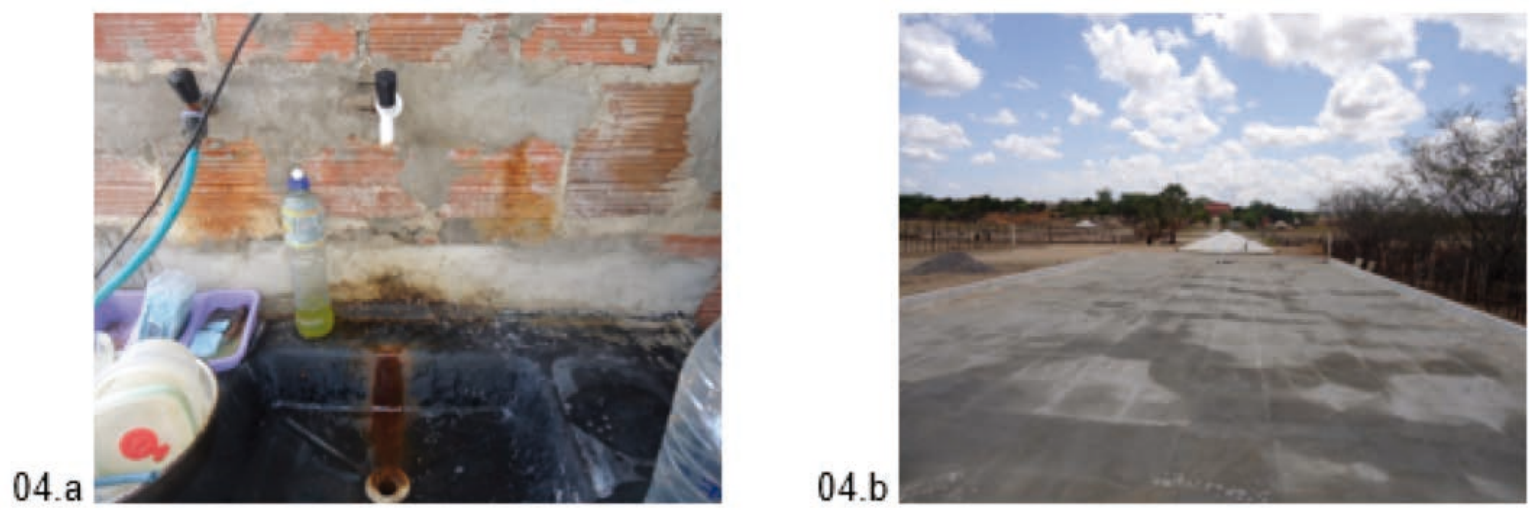

Figura 04 - Usos múltiplos da água na área no CPCA, 2014. (a) Uso doméstico em Piquiri II em Mossoró. (b) Cisterna com calçadão de concreto para irrigações em Serra Vermelha em Areia Branca.

Fonte: Pinto Filho (2018).

O abastecimento humano nas comunidades analisadas vem se consolidando com a efetiva participação da população local nas construções de cisternas (Figura 05.a), reservatórios inferiores (Figura 05.b), reservatórios superiores, calçadas de concreto para captação de águas pluviais e adutoras. 

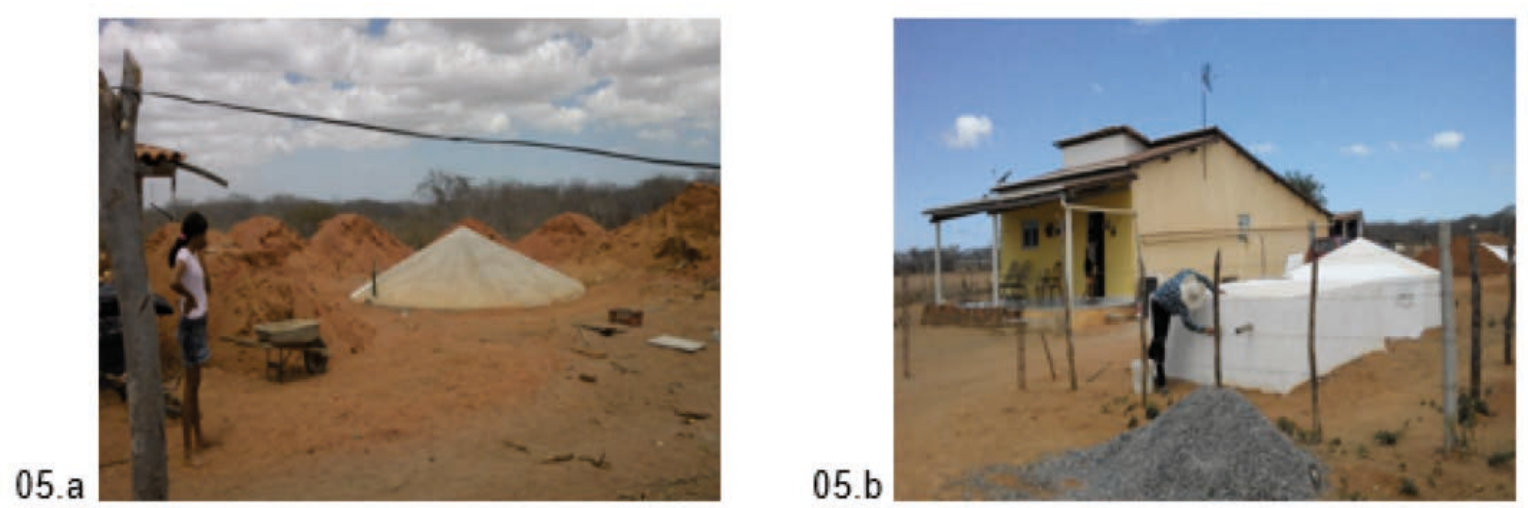

Figura 05 - Participação da população na construção do abastecimento de água das comunidades no CPCA, 2014. (a) Comunidade Sussuarana em Mossoró. (b) Comunidade Gravelos em Areia Branca.

Fonte: Pinto Filho (2018).

\subsection{PERCEPÇÃO AMBIENTAL DO ABASTECIMENTO HUMANO DE ÁGUA NAS COMUNIDADES RURAIS DO CPCA/RN}

Embora o abastecimento de água seja crucial para saúde, pode haver problemas nas fases de coleta, transporte, armazenamento e extração da água (WRIGHT et al. 2004; VARGHESE, 2004). Nas comunidades rurais do CPCA/RN observou-se que o abastecimento apresenta variabilidade em sua distribuição por finalidade, sendo para beber: carro-pipa $(44,06 \%)$, poço $(27,81 \%)$, água mineral $(23,13 \%)$ e outros $(5 \%)$; para limpeza de frutas e legumes: carro-pipa $(61,55 \%)$, poço $(36,25 \%)$ e outros $(2,20 \%)$; para limpeza de utensílios de manipulação de alimentos: carro-pipa $(61,25 \%)$, poço $(36,55 \%)$ e outros $(2,20 \%)$.

O quadro de riscos à saúde humana em virtude das irregularidades no abastecimento de água tornase mais preocupante devido à forma de tratamento de água adotada pela população, tendo em vista que $42,2 \%$ da população bebe água sem tratamento, $26,6 \%$ água de filtro, $22,2 \%$ água mineral, 6,6\% água com cloro, $1,9 \%$ água fervida e $0,6 \%$ outras formas de tratamentos. Esse cenário acentua-se por meio do consumo de água quando $78,4 \%$ da população realiza a limpeza de legumes e frutas sem tratamento prévio, $10 \%$ com filtro, $7,2 \%$ com cloro, 2,2\% com fervura, 1,3\% com água sanitária e $0,9 \%$ com outros tipos de tratamentos. Essa vulnerabilidade é consolidada a partir do uso da água sem tratamento para limpeza de utensílios de manipulação de alimentos por $81,25 \%, 10 \%$ com filtro, 5,63\% com cloro, $2,81 \%$ com fervura e $0,31 \%$ com outras maneiras de tratamentos.

O abastecimento de água para consumo humano das comunidades pesquisadas é avaliado pela população de forma positiva, sendo os aspectos qualitativos aqueles com maior aceitação (Figura 06.a) em comparação com os quantitativos (Figura 06.b). O critério de quantidade da água obteve avaliação inferior quando comparado com a qualidade na percepção dos moradores. Essa avaliação positiva está relacionada ao que é evidenciado na Figura 06.c; os usuários consideram que os principais problemas no abastecimento são pouca água (29,35\%); frequência irregular (66,30\%) e pouca água e frequência irregular (4,35\%). O contexto de escassez e irregularidade na distribuição conduz os entrevistados a uma avaliação de qualidade e quantidade boas. 


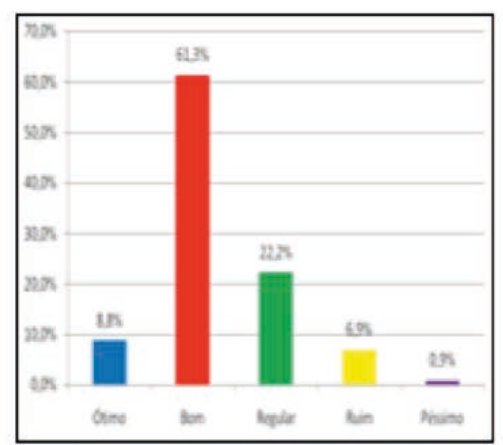

06.a - Qualidade da água

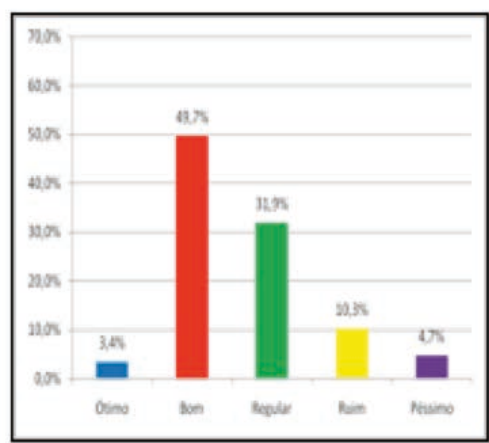

06.b - Quantidade da água

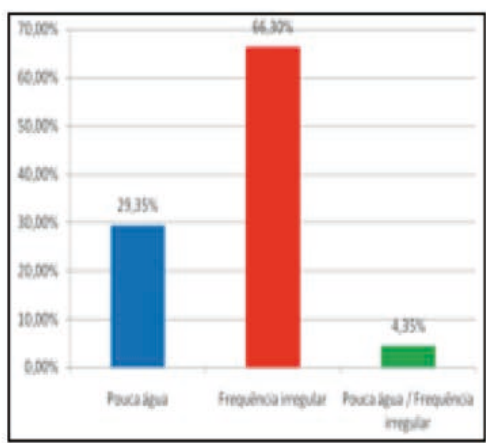

06.c - Principais problemas

Figura 06 - Avaliação da qualidade (a), quantidade (b) e problemas do abastecimento humano (c) de água pelos moradores das comunidades rurais do CPCA, 2014.

Fonte: Pinto Filho (2018).

O padrão de qualidade de vida de uma população está diretamente relacionado à disponibilidade e qualidade de sua água, sendo esta o recurso natural mais crítico à saúde humana e mais susceptível a impor limites ao desenvolvimento (HELLER, 1997). Nas comunidades rurais investigadas, os problemas no sistema de abastecimento de água podem interferir na saúde humana, já que algumas doenças de veiculação hídrica, como diarreia $(10,5 \%)$ e dengue $(3,4 \%)$, estão entre as mais citadas pelos moradores (Figura 07). Nos estudos de Prosenewicz e Lippi (2012), os pescadores ribeirinhos do Rio Machado de Ji-Paraná (RO) relataram problemas de saúde, como dores na coluna, nas pernas, musculares, cãibras, problemas de visão, dor de cabeça, gripe e doenças de pele. A relação da qualidade da água na ocorrência de doenças também foi investigada por Queiroz, Heller e Silva (2009) concluindo que existe influência desse recurso natural na ocorrência de diarreia aguda na população da cidade de Vitória (ES).

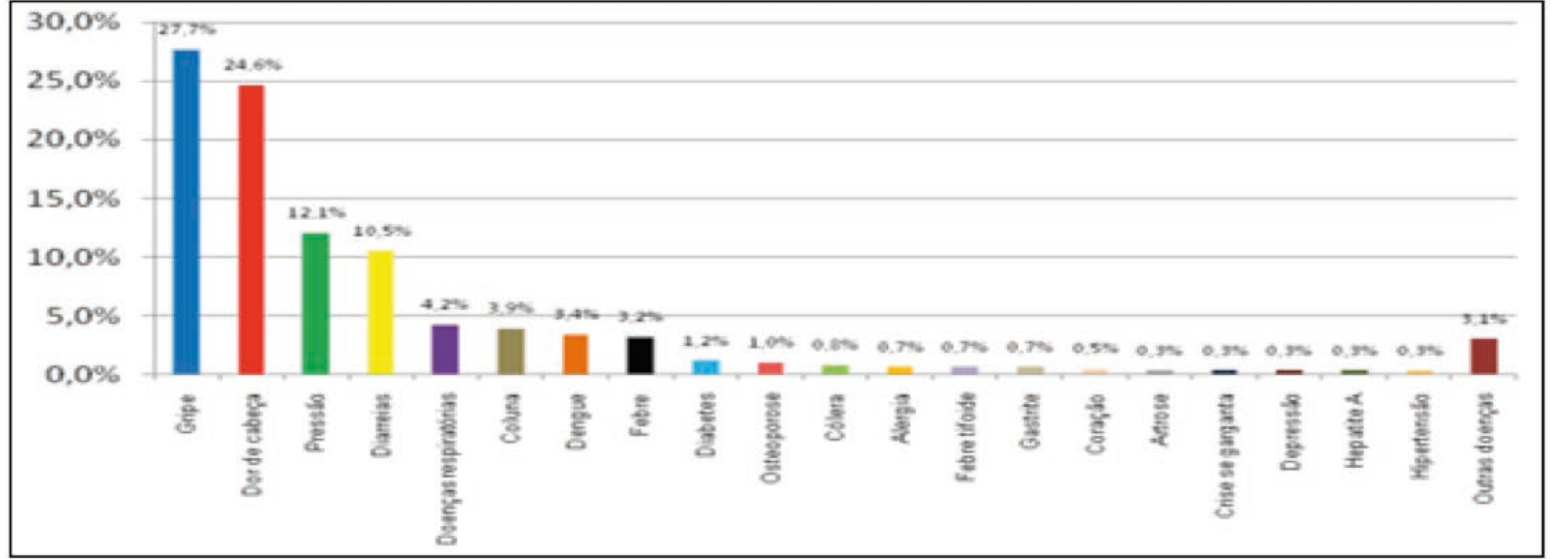

Figura 07 - Doenças citadas pelos moradores das comunidades rurais no CPCA, 2014.

Fonte: Pinto Filho (2018).

\subsection{QUALIDADE DA ÁGUA DO ABASTECIMENTO HUMANO NAS COMUNIDADES RURAIS DO CPCA/RN}

A Tabela 04 contém os resultados das variáveis físico-químicas das amostras de água para consumo humano nas comunidades rurais do CPCA/RN. A Turbidez - Tur pode ser tanto de origem natural quanto antrópica e não traz problemas diretos, porém, esteticamente é desagradável e os sólidos em suspensão podem servir de abrigo para microrganismos patogênicos (PERPÉTUO, 2014). 
Os resultados obtidos de Tur (Tabela 04) variaram entre 0,17 e 6,61 Unidades Nefelométricas de Turbidez (UNT), com média de 1,04 UNT. Esses dados foram inferiores ao limite máximo permitido (até 40 UNT) proposto pela Resolução Conama $n^{\circ} 357 / 2005$ para águas doces de classe 1 , de abastecimento para consumo humano, com desinfecção, apontando que estão conforme condições estéticas. Entretanto, quando comparado com o da Portaria MS no 2.914/2011, observa-se que a amostra 16 apresentou resultados considerados não aceitáveis para consumo humano, pois apresentou valor superior ao limite recomendado de 5 UNT, necessitando de tratamento prévio para consumo.

Esses resultados obtidos para Tur foram inferiores aos determinados por outros estudos para águas superficiais na mesma na Bacia Hidrográfica, já que Araújo, Santos e Araújo (2007) determinaram valores entre 6,13 e 37,79 UNT; Bezerra et al. (2013) encontraram teores de 21,00 a 100,10 UNT e Silva e Souza (2013) determinaram valor médio de 7,94 no período chuvoso e 17,65 no período de estiagem. Tal comportamento deve-se ao fato de que as águas subterrâneas têm baixos valores de turbidez, devido ao efeito filtro do solo (FEITOSA; MANOEL FILHO, 2000). Quando comparados com outras realidades, como aquíferos rasos, como o Barreiras, em Natal/RN, observa-se que o presente estudo apresentou semelhanças, uma vez que Stein et al. (2012) apresentaram valores entre 0,40 a 15,00 UNT. Dessa forma, pode-se inferir que os valores encontrados apresentam normalidades para corpos hídricos subterrâneos, porém, com alerta para consumo humano.

O potencial Hidrogeniônico - pH pode ser resultado de fatores naturais e antrópicos (LIBÂNIO, 2005). Os valores do $\mathrm{pH}$ das amostras de água estudadas variaram entre 7,10 a 8,20 com média de 7,72 (Tabela 04). Ressalta-se ainda que tais valores se encontram em conformidade com a Resolução Conama $n^{\circ}$ 357/2005 e a Portaria MS no 2.914/2011, que preveem valores máximos permitidos entre 6,0 a 9,0 e 6,0 a 9,5 , respectivamente.

Esses resultados apresentaram comportamento semelhante aos dados obtidos para águas superficiais da BHRAM/RN por Araújo, Santos e Araújo (2007) que ficaram entre 7,96 a 8,23; por Lemos, Ferreira Neto e Dias (2009) que obtiveram resultados próximos de 8,0; por Bezerra et al. (2013) que oscilou entre 7,9 a 8,3; Silva e Souza (2013) que estendeu entre 6,93 a 8,46. Entretanto, quando comparados com os dados determinados por Stein et al. (2012) para o aquífero Barreiras em Natal/RN, verificase que foram superiores, já que esses autores encontraram valores entre 4,30 a 7,10, com reação ligeiramente ácida. Portanto, pode-se inferir que os valores do $\mathrm{pH}$ das amostras estudadas encontramse próximos da neutralidade, sendo considerada água com boa qualidade.

A Condutividade Elétrica - CE representa uma medida do efeito antrópica, já que depende das concentrações iônicas e da temperatura, indicando a existência de sais na água (COMPANHIA AMBIENTAL DO ESTADO DE SÃO PAULO - CETESB, 2010). Os resultados de CE (Tabela 04) ficaram compreendidos entre 245,00 a $817,00 \mu \mathrm{s} / \mathrm{cm}$ com média de $533,60 \mu \mathrm{s} / \mathrm{cm}$, sendo considerados aceitáveis, tendo em vista que por critérios organolépticos a Portaria MS $n^{\circ}$ 2.914/2011 estabelece como padrão de aceitação para consumo um limite de $1.000 \mu \mathrm{s} / \mathrm{cm}$ (BRASIL, 2011). Não foi possível fazer enquadramento com a Resolução Conama $n^{\circ} 357 / 2005$ devido à falta de valores para esse parâmetro. Quando comparados com os resultados de Stein et al. (2012) para águas subterrâneas, observam-se diferenças significativas, já que esses autores encontraram valores entre 45,90 a 113,00 . Portanto, embora os resultados obtidos sejam considerados aceitáveis devido atender à legislação vigente e estarem abaixo da literatura, merece destaque para amostras que já estão próximas do limite, devido ao controle dessas concentrações abaixo dos limites previstos é ferramenta ímpar para se evitar os efeitos degradantes do processo de poluição hídrica (TUNDISI, 2003).

Os valores Dureza Total - DT (Tabela 04) estão na faixa entre 16,20 a 72,00 mg/L, com média de 44,74 $\mathrm{mg} / \mathrm{L}$. Nesse caso, $80 \%$ das águas estudadas são consideradas brandas (dureza até $60 \mathrm{mg} / \mathrm{L}$ de CaCO3) e os $20 \%$ restantes são moderadamente duras (61 a $120 \mathrm{mg} / \mathrm{L}$ de CaCO3), caso das amostras 04, 07, 14, 15 e 16, registrando assim em todas as amostras conformidade com a Portaria MS n².914/2011, já que o Valor Máximo Permitido - VPM é de 500 mg/L (BRASIL, 2011).

Com a Resolução Conama $n^{\circ} 357 / 2005$, não foi possível fazer comparação tendo em vista a falta de valores para esse parâmetro. Evidencia-se que a situação se repete no contexto do semiárido, já 
que Landim Neto et al. (2013) encontraram valores semelhantes para o período chuvoso para águas subterrâneas em Aquiraz, CE. Entretanto, esses dados foram superiores aos encontrados por Stein et al. (2012) para aquífero Barreiras que determinaram a média da dureza total de $16,42 \mathrm{mg} / \mathrm{L}$. Portanto, pode-se inferir que as amostras consideradas moderadamente duras podem resultar em inconvenientes como a dificuldade de formação de espuma com o sabão e a formação de incrustações de carbonato ou silicato de cálcio e, ou magnésio, que abaixam a condutividade térmica e promovem a corrosão interna de caldeiras e outras unidades onde ocorre elevação de temperatura (MIERZWA; HESPANHOL, 2005).

O nitrogênio tem diversos estados de oxidação (amônia - NH3, nitrito - NO2- e nitrato - NO3-), onde, para Scorsafava et al. (2010), a presença de compostos de nitrogênio nos seus diferentes estados pode ser um indicativo de contaminação hídrica e de possíveis condições higiênico-sanitárias insatisfatórias. Nas amostras de água analisadas, o teor de NH3 (Tabela 04) variou entre 0,24 a 0,70 mg/L, com média de $0,39 \mathrm{mg} / \mathrm{L}$. Tais valores estão conformes com a Portaria MS $\mathrm{n}^{\circ} 2.914 / 2011$, sendo inferiores ao valor máximo permitido que é de $1,5 \mathrm{mg} / \mathrm{L}$ (BRASIL, 2011). Não se comparou com a Resolução Conama $\mathrm{n}^{\circ}$ $357 / 2005$, devido à falta de valores para esse critério. Ressalta ainda que os valores obtidos foram inferiores aos de outras comunidades do semiárido, já que Landim Neto et al. (2013) têm valores entre 0,50 a 1,50 mg/L. Para tanto, embora os valores encontrados estejam atendendo à legislação ambiental e sejam inferiores aos da literatura, merece atenção pela presença desses elementos, já que são considerados indicativo negativo da alteração da qualidade ambiental.

O NO2- apresentou resultados Abaixo do Limite de Detecção (Tabela 04), com exceção das amostras 08, 17, 18 e 19, que apresentaram teores de $0,01 \mathrm{mg} / \mathrm{L}$. Mesmo nesses casos, os valores foram inferiores aos valores máximos permitidos para a Resolução Conama n³57/2005 e a Portaria MS no 2.914/2011, que é de $1,0 \mathrm{mg} / \mathrm{L}$ de $\mathrm{N}$. As amostras 17, 18 e 19 localizam-se na comunidade rural de Sussuarana, Mossoró/RN, região com maior núcleo habitacional da área investigada, sendo 110 domicílios distribuídos próximos um do outro, com a inexistência de esgotamento sanitário, favorecendo a ocorrência de NO2- nessas amostras de água.

Os teores de NO3- (Tabela 04) variaram entre 0,02 a 1,57 mg/L, apresentando teor médio de 0,41 mg/L, com a presença desse nutriente em todas as amostras coletadas nas comunidades rurais de Mossoró/ RN. Constata-se que todos os teores apresentados de nitrato foram inferiores aos valores máximos permitidos para a Resolução Conama n 357/2005 e a Portaria MS no 2.914/2011, que é de 10,0 mg/L de $\mathrm{N}$, observando atendimento à legislação aplicável. Esses dados foram inferiores aos encontrados por Stein et al. (2012) que variaram entre 0,16 e 4,15 mg/L de $\mathrm{N}$ com média de 1,00 mg/L de N. Mesmo em pouca quantidade e menores valores quando comparados com outras situações, a presença do NO3- em algumas amostras de água deve servir de alerta, uma vez que evidenciam o processo inicial de alteração da qualidade natural dessa fonte hídrica por espécies nitrogenadas. De acordo com Stein et al. (2012), o NO3- é uma espécie química persistente, móvel e que não degrada facilmente em meio aeróbico subterrâneo, com facilidade de migração. Portanto, o Nitrato é um parâmetro que merece cuidado e monitoramento constante, já que em elevadas concentrações de Nitrato podem causar graves problemas aos ecossistemas aquáticos, trazendo prejuízos a todos que se beneficiam do recurso (MAGINI et al., 2007).

O Ca e o Mg são elementos essenciais para a saúde humana, porém, em excesso podem resultar em diversos efeitos deletérios. $\mathrm{Na}$ água esses elementos apresentam comportamentos muito parecidos, com valores significativamente maiores do Ca. O teor de Ca nas águas estudadas variou de 2,94 a 18,36 $\mathrm{mg} / \mathrm{L}$, com média de 11,09 mg/L. O Mg oscilou de 1,30 a 10,41 mg/L com média de 4,43 mg/L (Tabela 04). Para ambos os elementos, a Resolução Conama $n^{\circ}$ 357/2005 e a Portaria MS no 2.914/2011 não apresentam orientações, porém, com base na Resolução Conama no 396/2008 (BRASIL, 2008), o limite de dureza para a água potável (Ca e Mg) deve ser de 500 mg.L-1, indicando que a água se apresenta com boa qualidade para uso e consumo humano.

Esses valores obtidos foram superiores quando comparados com os dados de Menezes et al. (2013) que determinaram valores de Ca entre 0,00 a 1,00 mg/L com média de $0,02 \mathrm{mg} / \mathrm{L}$ e de $\mathrm{Mg}$ entre 0,18 e 4,09 mg/L, com média de 0,89 mg/L. Entretanto, foram inferiores aos evidenciados por Obiefuna e 
Sheriff (2011) para águas subterrâneas na Nigéria que foram entre 10,00 a 100,00 mg/L de Ca e entre 1,00 a 40,00 mg/L de Mg. Desse modo, observa-se que esses elementos são considerados aceitáveis para consumo humano, porém, precisam de monitoramento constante para evitar possíveis riscos à saúde humana.

A média dos resultados analíticos do Ferro - Fe (Tabela 04) para as águas investigadas foi de $0,07 \mathrm{mg} / \mathrm{L}$, variando de 0,02 a 0,20 mg/L. Quando comparados com a Resolução Conama n 357/2005 e a Portaria MS no 2.914/2011, observa-se que foram inferiores ao valor máximo permitido que é de 0,3 mg/L para ambas situações. Os teores obtidos de Fe deste estudo foram semelhantes em comparação à realidade do aquífero Barreiras, uma vez que Stein et al. (2012) obtiveram média de 0,15 mg/L de Fe, variando entre 0,03 a $0,28 \mathrm{mg} / \mathrm{L}$ de Fe. Ressalta ainda que esses dados foram inferiores aos obtidos por Landim Neto et al. (2013) para poços de áreas de sedimentos ricos em Fe em Trairussu, Aquiraz, CE.

O Oxigênio Dissolvido - OD é o principal parâmetro de caracterização dos efeitos da poluição das águas por despejos orgânicos (VON SPERLING, 2005). Esse elemento influencia todos os processos químicos e biológicos que ocorrem na água e indica possível poluição por matéria orgânica (ESTEVES, 2011). Nas amostras analisadas, os valores de OD (Tabela 04) oscilaram entre 3,89 a 7,60 mg/L, com média de $5,80 \mathrm{mg} / \mathrm{L}$. Os menores valores foram evidenciados nas águas provenientes de abastecimento de poço, nas comunidades rurais de Mossoró-RN, onde $84,61 \%$ das análises foram inferiores a $6,0 \mathrm{mg} / \mathrm{L}$, não atendendo à Resolução Conama $n^{\circ} 357 / 2005$. Entretanto, não foi possível estabelecer comparação com a Portaria MS no 2.914/2011devido à falta de valores para esse parâmetro.

Ressalta-se ainda que esses resultados foram similares aos valores de águas de rios da BHRAM/RN encontrados por Bezerra et al. (2013); Araújo, Santos e Araújo (2007) e Silva e Souza (2013) para o período chuvoso. Tal situação pode ser explicada pelo fato de que no período em que há maior presença de matéria orgânica no meio aquático, menores são as concentrações de OD, ou seja, há uma relação direta entre matéria orgânica e a concentração de OD (SIQUEIRA; APRILE; MIGUEIS, 2012). Portanto, os baixos valores de OD podem ser um indicativo do consumo pela decomposição da matéria orgânica ou oxidação de íons metálicos.

O Teor de Óleo e Graxas - TOG é amplamente utilizado como parâmetro de qualidade da água. Para o Instituto Mineiro de Gestão das Águas - IGAM (2015), a presença de óleos e graxas na água pode constituir um sério problema no tratamento de água devido a sua pequena solubilidade. Observou-se em todas as amostras analisadas o conteúdo de TOG (Tabela 04) com teores que variam de 0,36 a 6,10 $\mathrm{mg} / \mathrm{L}$, com teor médio de $1,42 \mathrm{mg} / \mathrm{L}$, considerando nesse caso uma não conformidade, que resulta em uma área com vulnerabilidade de saúde ambiental, principalmente porque a Resolução Conama $\mathrm{n}^{\circ}$ $357 / 2005$ prevê que óleos e graxas devem ser virtualmente ausentes.

O cenário torna-se mais alarmante, tendo em vista que os resultados obtidos foram superiores aos de Santi et al. (2013), já que esses autores determinaram teores de óleos e graxas variando entre 0,01 a $0,14 \mathrm{mg} / \mathrm{L}$. Dados semelhantes aos deste estudo foram encontrados por Zan et al. (2012), pois os teores de óleos e graxas oscilaram entre 1,20 e a $6,30 \mathrm{mg} / \mathrm{L}$. Entretanto, foram inferiores aos obtidos por Forte et al. (2007), uma vez que os teores de óleos e graxas foram entre 19,00 e 193,00 mg/L. Diante dessa situação, observou-se que a população local adota a técnica de armazenar água por alguns dias antes de ser utilizada com a finalidade de o óleo assentar, tornando-se assim evidente a separação da água e óleo. Assim, infere-se que a realidade da área de estudo aproxima-se de local com intervenção industrial, necessitando do acompanhamento periódico desses compostos para que seus valores não resultem em sérios riscos à saúde humana e da identificação de outras possíveis fontes desses compostos orgânicos, principalmente porque esses produtos são de difícil controle, podendo provocar lesões materiais e ecológicas de grandes proporções a esse sistema, além de enfermidades ou até a morte de seres vivos resultantes da exposição de pessoas, animais e vegetais a agentes ou condições ambientais potencialmente perigosas (SZEWCZYK, 2011).

Ressalta-se ainda que o óleo pode interferir nos processos vitais à reprodução, mesmo em baixas concentrações. Com alteração no ciclo reprodutivo, toda a cadeia alimentar é afetada, o que consequentemente acarretará danos irreparáveis ao ecossistema (BíCEGO, 2008). Reforçando tal linha 
de pensamento de consequências da presença de óleo em água, Derísio (2012) aponta que a ocorrência de óleos e graxas no abastecimento público de água pode ocasionar sabor e odor indesejáveis e problemas sanitários, como o surgimento de doenças.

Tabela 04 - Estatística descritiva das características físico-químicas das amostras de água por comunidades rurais do CPCA/RN, 2014

\begin{tabular}{|c|c|c|c|c|c|c|c|c|c|c|c|c|}
\hline Pontos & \multicolumn{12}{|c|}{ Características Físico-químicas } \\
\hline 01 & $\mathrm{ALD}^{6}$ & 7,10 & 488,00 & 50,40 & 0,30 & ALD & ALD & 14,69 & 3,47 & 0,06 & 6,20 & 2,48 \\
\hline 02 & 0,17 & 7,50 & 489,00 & 48,60 & 0,30 & ALD & 0,22 & 13,95 & 3,47 & 0,07 & 6,00 & 2,46 \\
\hline 04 & 0,68 & 7,70 & 502,00 & 66,60 & 0,31 & ALD & ALD & 13,95 & 7,81 & 0,20 & 6,10 & 6,10 \\
\hline 05 & ALD & 8,10 & 394,00 & 48,60 & 0,34 & ALD & 0,07 & 14,69 & 3,04 & 0,16 & 6,50 & 0,45 \\
\hline 06 & ALD & 8,00 & 546,00 & 43,20 & 0,24 & ALD & 0,15 & 14,69 & 1,74 & 0,12 & 6,40 & 0,53 \\
\hline 07 & ALD & 7,70 & 515,00 & 66,60 & 0,26 & ALD & 0,09 & 9,55 & 10,41 & 0,20 & 6,30 & 1,62 \\
\hline 10 & ALD & 7,90 & 245,00 & 36,00 & 0,27 & ALD & 0,06 & 8,81 & 3,47 & 0,02 & 7,50 & 0,99 \\
\hline 11 & ALD & 7,80 & 319,00 & 25,20 & 0,26 & ALD & 0,04 & 6,61 & 2,17 & 0,02 & 7,60 & 2,05 \\
\hline 12 & ALD & 7,90 & 479,00 & 41,40 & 0,27 & ALD & 0,08 & 6,61 & 6,07 & 0,02 & 7,10 & 1,64 \\
\hline Média ${ }^{1}$ & 0,13 & 7,74 & 454,42 & 48,30 & 0,28 & 0,00 & 0,06 & 11,93 & 4,59 & 0,09 & 6,49 & 1,67 \\
\hline 13 & 0,34 & 7,40 & 786,00 & 57,60 & 0,46 & ALD & 0,39 & 14,69 & 5,21 & 0,06 & 4,60 & 2,47 \\
\hline 14 & 2,20 & 7,50 & 802,00 & 63,00 & 0,42 & ALD & 0,24 & 15,42 & 6,07 & 0,05 & 4,50 & 1,03 \\
\hline 15 & 2,54 & 7,70 & 809,00 & 68,40 & 0.57 & ALD & 0,21 & 16,89 & 6.51 & 0,05 & 4,48 & 1,71 \\
\hline 21 & ALD & 7,70 & 484,00 & 27,00 & 0,40 & ALD & 1,34 & 8,81 & 1,30 & 0,06 & 5,25 & 0,80 \\
\hline 22 & ALD & 7,70 & 484,00 & 30,60 & 0,70 & ALD & 1,36 & 9,55 & 1,74 & 0,06 & 5,80 & 1,17 \\
\hline 23 & 4,07 & 7,50 & 582,00 & 34,00 & 0,59 & ALD & 0,05 & 11,02 & 6,51 & 0,04 & 6,70 & 1,73 \\
\hline 24 & 4,58 & 7,50 & 582,00 & 54,00 & 0,70 & ALD & 0,05 & 11,01 & 6,53 & 0,03 & 5,52 & 1,88 \\
\hline 25 & 4,07 & 7,50 & 581,00 & 53,10 & 0,69 & ALD & 0,05 & 11,38 & 6,07 & 0,04 & 6,01 & 1,77 \\
\hline Média $^{2}$ & 1,88 & 7,70 & 606,69 & 41,45 & 0,48 & 0,00 & 0,74 & 10,31 & 4,27 & 0,05 & 5,16 & 1,20 \\
\hline Média $^{8}$ & 1,04 & 7,72 & 533,60 & 44,74 & 0,39 & 0,00 & 0,41 & 11,09 & 4,43 & 0,07 & 5,80 & 1,42 \\
\hline $\mathrm{DP}^{4}$ & 1,86 & 0.24 & 140,81 & 16,79 & 0,15 & 0,00 & 0,58 & 4,31 & 2,30 & 0,05 & 0,99 & 1,20 \\
\hline Mínimo & 0,17 & 7,10 & 245,00 & 16,20 & 0,24 & 0,01 & 0,00 & 2,94 & 1,30 & 0,02 & 3,89 & 0,36 \\
\hline Máximo & 6,61 & 8,20 & 817,00 & 72,00 & 0,70 & 0,01 & 1,57 & 18,36 & 10,41 & 0,20 & 7,60 & 6,10 \\
\hline $\mathrm{CV}^{5}(\%)$ & 179,49 & 3,11 & 26,39 & 37.52 & 39,82 & 32,52 & 139,61 & 38,85 & 51,95 & 78,11 & 17.01 & 83,97 \\
\hline
\end{tabular}

${ }^{1}$ Média das amostras de água com origem de carro-pipa das comunidades de Areia Branca-RN; ${ }^{2}$ - Média das amostras de água com origem de poço das comunidades de Mossoró-RN; ${ }^{3}$ - Média de todas as amostras de água coletadas; $4-D P=$ Desvio Padrão; 5 - CV = Coeficiente de Variação; 6-ALD = Abaixo do Limite de Detecção.

Fonte: Pinto Filho (2018).

A Tabela 04 permite ainda a comparação das médias dos valores de parâmetros físico-químicos obtidos em amostras de água trazidas por carro-pipa para abastecimento das comunidades rurais de Areia Branca e amostras de água de poços das comunidades rurais de Mossoró. Turbidez e condutividade elétrica apresentam maiores valores nas amostras de água de poço. A média dos valores de $\mathrm{pH}$ é 7,7 em ambos os casos. A média de amônia, nitrito e nitrato é maior nas amostras de água de poço; das 12 amostras de água provenientes de abastecimento por carro-pipa, oito apresentaram nitrato, com um teor médio de $0,06 \mathrm{mg} / \mathrm{L}$; as 13 amostras provenientes dos poços, todas com nitrato, forneceram um valor médio de $0,74 \mathrm{mg} / \mathrm{L}$ de nitrato. Esse fato indica fontes de contaminação próxima dos poços que abastecem as comunidades rurais. A média dos valores de OD é mais baixa para as amostras de água dos poços, o que é esperado pela menor aeração e pela provável presença de matéria orgânica, indicada pelos compostos nitrogenados. Embora o teor de óleos e graxas das amostras trazidas por carros-pipa seja maior, cumpre ressaltar que esse valor deveria ser zero para qualquer das amostras.

Os resultados dos metais pesados das amostras de água analisadas foram todos Abaixo do Limite de Detecção - ALD para os valores de $\mathrm{Cd}, \mathrm{Cu}, \mathrm{Cr}$ e $\mathrm{Pb}$ pela metodologia utilizada, sendo possível ter sido influenciadas pela estação climatológica (ARAÚjO et al., 2018). As concentrações de Zn variam entre 0,02 e 0,04 mg/L, com média de $0,01 \mathrm{mg} / \mathrm{L}$, atendendo às legislações pertinentes, sendo o valor máximo de 0,18 mg/L para a Resolução Conama $n^{\circ} 357 / 2005$ e o limite de 5,00 mg/L para a Portaria MS no 2.914/2011.

Para tanto, há irregularidades no abastecimento de água da população das comunidades rurais do CPCA/ RN no acesso, na distribuição e na qualidade da água, principalmente porque não são consideradas prioridades na saúde de nível local, uma vez que Bevilacqua et al. (2014) definem que essas ações 
impactam em médio e longo prazo. Esse panorama para começar a ser revertido deverá incluir ações de educação sanitária com maior participação social, visto que são consideradas complemento indispensável na busca de melhores condições de saúde e qualidade de vida em áreas de exclusão social (RAZZOLINI; GUNTHER, 2008).

\section{CONSIDERAÇÕES FINAIS}

O abastecimento de água das comunidades rurais do Campo Petrolífero Canto do Amaro - CPCA/RN ocorre por meio de carro-pipa nas localidades de Areia Branca/RN e poço na zona rural de Mossoró/ $\mathrm{RN}$, com irregularidades na forma de armazenamento de água e no tratamento utilizado antes do consumo humano. Apesar dessas anormalidades, esse recurso vem sendo usado para vários fins, como no uso doméstico na zona rural de Mossoró e em pequenas irrigações a partir de cisternas no meio rural de Areia Branca.

O uso doméstico da água nas comunidades investigadas tem variação em sua origem, sendo para beber: $44,06 \%$ de carro-pipa, $27,81 \%$ de poço e $23,13 \%$ de água mineral; para limpeza de frutas e legumes: $61,55 \%$ de carro-pipa e $36,25 \%$ de poço; e para limpeza de utensílios de manipulação de alimentos: $61,25 \%$ de carro-pipa e $36,55 \%$ de poço.

A forma de usos da água na área de estudo contribui para um quadro de riscos à saúde humana, já que $42,2 \%$ da população bebe água sem tratamento, $78,4 \%$ da população limpa legumes e frutas com água sem tratamento e $81,25 \%$ da população utiliza utensílios de manipulação de alimentos lavados com água sem tratamento, sendo evidenciado a partir da ocorrência de doenças de veiculação hídrica, como diarreia e dengue.

Na avaliação da qualidade da água, os parâmetros de Turbidez, pH, Condutividade Elétrica, Dureza Total, Amônia, Nitrito, Nitrato e Ferro apresentaram comportamentos de padrões aceitáveis para consumo humano. Os teores de $\mathrm{Ca}$ e $\mathrm{Mg}$ foram semelhantes aos de outros trabalhos em comunidades rurais e também não apresentaram riscos para o consumo humano.

O Oxigênio Dissolvido foi o que apresentou comportamento mais indesejável, com valores oscilando entre 3,89 e 7,60 mg/L, apresentando $84,61 \%$ das amostras inferiores a $6 \mathrm{mg} / \mathrm{L}$, não atendendo à Resolução n 357/2005 do Conama, para águas de classe 1.

O cenário de vulnerabilidade da saúde ambiental da área pesquisada torna-se mais evidente a partir da constatação de que em todas as amostras de água analisadas verificou-se a presença de óleos e graxas com teores que variam de 0,36 a $6,10 \mathrm{mg} / \mathrm{L}$, possibilitando a existência de um problema no tratamento de água devido a sua pequena solubilidade e uma fonte potencial de poluição e contaminação ambiental, representando dessa forma um risco à saúde humana.

Os resultados dos metais pesados das amostras de água investigadas a partir da técnica adotada não foram quantificados, com exceção do Zn, que apresentou concentrações que variam entre 0,01 e 0,04 $\mathrm{mg} / \mathrm{l}$. Entretanto, esses valores ainda estão dentro dos limites aceitáveis das legislações pertinentes, porém, ainda não se pode assegurar ausência de risco para a saúde ambiental.

Para atenuar a problemática do sistema de abastecimento de água da população da área investigada, faz-se necessário adotar ações de melhorias, como por exemplo: maior frequência no abastecimento; maior disponibilidade hídrica; universalização do abastecimento; efetivação dos componentes de saneamento ambiental na área; execução de projetos de educação ambiental e sanitária e monitoramento ambiental do abastecimento público de forma periódica.

Diante dessa situação, recomendam-se novas investigações da qualidade da água com parâmetros físico-químicos, bacteriológicos e análise de hidrocarbonetos nos períodos chuvosos e de estiagem, com a finalidade de correlacionar os teores obtidos com os índices pluviométricos da região para verificar se a qualidade da água permanece constante ou apresentou algum resultado indesejável. 


\section{REFERÊNCIAS}

APHA - AWWA - WPCF. Standart methods for the examination of water and wastewater. 19th edition. Wasghington D.C. American Public Health Association.1995. 953p.

ARAÚJO, J. C. de. et al. Comparação de métodos para quantificação de bactérias nitrificantes. Eng. Sanit. Ambient., Mar 05, 2018.

ARAÚJO, V. S.; SANTOS, J. P.; ARAÚJO, A. L. C. Monitoramento das águas do Rio Mossoró/RN, no período de abril/2005 a julho/2006. Holos. A. 3, maio de 2007.

BABBIE, E. Métodos de Pesquisas de Survey. Belo Horizonte: UFMG, 2001.

BEVILACQUA, P. D. et al. Vigilância da qualidade da água para consumo humano no âmbito municipal: contornos, desafios e possibilidades. Saúde e Sociedade, v. 23, n. 2, p. 467-483, 2014.

BEZERRA, J. M. et al. Análise dos indicadores de qualidade da água no trecho urbano do Rio Apodi-Mossoró em Mossoró-RN, Brasil. Semina: Ciências Agrárias, v. 34, n. 6, suplemento 1, p. 3443-3454, 2013.

BHATTI, M. T.; LATIF, M. Assessment of water quality of a river using an indexing approach during the low-flow season. Irrigation and Drainage. n. 60, p. 103-114, 2011.

BICEGO, M. C. et al. Poluição por petróleo. Poluição Marinha, Rio de Janeiro: Interciência, 2008.

BOLFARINE, H.; BUSSAB, W. O. Elementos de Amostragem. São Paulo: Blucher, 2005.

BRASIL. Ministério da Saúde. Portaria no 2.914 de 12 de dezembro de 2011. Dispõe sobre os procedimentos e responsabilidades relativos ao controle e vigilância da qualidade da água para consumo humano e seu padrão de potabilidade. Diário Oficial (da) República Federativa do Brasil, Brasília, DF, 2011. Disponível em: <http://www. comitepcj.sp.gov.br/download/Portaria_MS_2914-11.pdf>.

COMPANHIA AMBIENTAL DO ESTADO DE SÃO PAULO - CETESB. Variáveis da qualidade de água. 2010. Disponível em: <http://www.cetesb.sp.gov.br/agua/aguas-superficiais/109-variaveis-de-qualidade-das-aguas>. Acesso em: 05 ago. 2015.

CONSELHO NACIONAL DO MEIO AMBIENTE - CONAMA. Resolução no 357 de $\mathbf{1 7}$ de março de 2005. Dispõe sobre a classificação dos corpos de água e diretrizes ambientais para o seu enquadramento, bem como estabelece as condições e padrões de lançamento de efluentes. Ministério do Meio Ambiente. 2005.

CONSELHO NACIONAL DO MEIO AMBIENTE - CONAMA. Resolução no 396, de 3 de abril de 2008. Dispõe sobre a classificação e diretrizes ambientais para o enquadramento das águas subterrâneas e dá outras providências. Diário Oficial da União, Brasília, DF, 7 abr. 2008. Seção 1, p. 64-68.

DERÍSIO, J. C. Introdução ao Controle de Poluição Ambiental. Ed. Signus. 4. ed., São Paulo. 2012.

ESTEVES, F. A. Fundamentos de Limnologia. 3. ed. Rio de Janeiro: Interciência, 2011. 602p.

FEITOSA, F. A. C.; MANOEL FILHO, J. Hidrogeologia: conceitos e aplicações. Fortaleza: CPRM, LABHID - UFPE, 2. ed., 391 p., 2000.

GIATTI, L. L. Reflexões sobre Água de Abastecimento e Saúde Pública: um estudo de caso na Amazônia Brasileira. Saúde e Sociedade, v. 16, n. 1, p. 134-144, 2007.

GIL, A. C. Como elaborar projetos de pesquisa. 4. ed. São Paulo: Atlas, 2006.

HELLER, L. Saneamento e Saúde. Brasília: OPAS/OMS Representação do Brasil. 1997.

HORTELLANI, M. A. et al. Avaliação de contaminação por elementos metálicos dos sedimentos do Estuário Santos - São Vicente. Química Nova, v. 31, n. 1, p. 10-19, 2008. 
INSTITUTO MINEIRO DE GESTÃO DAS ÁGUAS. Parâmetros químicos. Disponível em: <http://aguas.igam.mg.gov. $\mathrm{br} /$ aguas/htmls/aminas_nwindow/param_quimicos.htm>. Acesso em: 16 maio 2015.

LANDIM NETO, F. O. et al. Avaliação da Qualidade da Água Subterrânea em Poços da Comunidade do Trairussu Inserida no Litoral Oriental do Ceará, Brasil. Espaço Aberto, PPGG - UFRJ, v. 3, n. 1, p. 173-188, 2013.

LEMOS, M.; FERREIRA NETO, M.; DIAS, N. S. Sazonalidade e variabilidade espacial da qualidade da água na Lagoa do Apodi, RN. Revista Brasileira de Engenharia Agrícola e Ambiental, v. 14, n. 2, p.155-164, 2010.

LIBÂNIO, M. Fundamentos de qualidade e tratamento de água. Campinas, SP: Editora Átomo, 2005.

MAGINI, C. et al. Avaliação ambiental da praia do Futuro, município de Fortaleza - Ceará. Revista de Geologia, Ceará, v. 20, n. 1, p. 91-98, Jun. 2007.

MAROTTA, H.; SANTOS, R. O. dos; ENRICH-PRAST, A. Monitoramento limnológico: um instrumento para a conservação dos recursos hídricos no planejamento e na gestão urbano-ambientais. Revista Ambiente e Sociedade. v. 11, n. 1. Campinas, 2008.

MELAZO, C. G. Percepção ambiental e educação ambiental: uma reflexão sobre as relações interpessoais e ambientais no espaço urbano. Olhares e Trilhas, v. 4, n. 6, p. 45-51, 2005.

MIERZWA, J. C.; HESPANHOL, I. Água na indústria: uso racional e reúso. São Paulo: Oficina de textos, 2005. 143p.

MILANI, E. J.; ARAÚJO, L. M. Recursos Minerais Energéticos: Petróleo Energy Mineral Resources: Petroleum. In: Bizzi, A. et al. (Ed.) Geologia, Tectônica e Recursos Minerais do Brasil. CPRM, Brasília, 2003.

OBIEFUNA, G. I.; SHERIFF, A. Assessment of Shallow Ground Water Quality of Pindiga Gombe Area, Yola Area, NE, Nigeria for Irrigation and Domestic Purposes. Research Journal of Environmental and Earth Sciences, v. 3, p. 131-141, 2011.

PERPÉTUO, E. A. Parâmetros de caracterização da qualidade das águas e efluentes industriais. São Paulo: CEPEMA-USP, 2014. 90p.

PINTO FILHO, J. L. O.; PETTA, A. R. Propostas de diretrizes de gestão ambiental para o campo petrolífero Canto do Amaro, RN, Brasil. Estudo \& Debate, Lajeado, v. 23, n. 2, p. 245-264, 2016.

PINTO FILHO, J. L. O.; PETTA, A. R.; SOUZA, R. F. Caracterização socioeconômica e ambiental da população do campo petrolífero Canto do Amaro, RN, Brasil. Sustentabilidade em Debate, v. 7, n. 2, p. 200-216, 2016.

PORTAL BRASIL. Pré-sal brasileiro tem produção recorde de petróleo e gás em dezembro. Editorial, 03/02/2014. Disponível em: <http://www.brasil.gov.br/economia-e-emprego/2014/02/pre-sal-brasileiro-tem-producaorecorde-de-petroleo-e-gas-em-dezembro>. Acesso em: 21 jan. 2015.

PROSENEWICZ, I.; LIPPI, U. G. Acesso aos Serviços de Saúde, Condições de Saúde e Exposição aos Fatores de Risco: percepção dos pescadores ribeirinhos do Rio Machado de Ji-Paraná, RO. Saúde e Sociedade, v. 21, n. 1, p. 219-231, 2012.

QUEIROZ, J. T. M.; HELLER, L.; SILVA, S. R. Análise da Correlação de Ocorrência da Doença Diarréica Aguda com a Qualidade da Água para Consumo Humano no Município de Vitória-ES, Saúde e Sociedade, v. 18, n. 3, p. 479489, 2009.

RAZZOLINI, M. T. P.; GUNTHER, W. M. R. Impactos na Saúde das Deficiências de Acesso à Água. Saúde e Sociedade, v. 17, n. 1, p. 21-32, 2008.

RODRIGUES, L. M. et al. A Percepção Ambiental como Instrumento de Apoio na Gestão e na Formulação de Políticas Públicas Ambientais. Saúde e Sociedade, v. 21, supl. 3, p. 96-110, 2012.

SANTI, G. M. et al. Variabilidade espacial de parâmetros e indicadores de Qualidade da água na sub-bacia hidrográfica do igarapé São Francisco, Rio Branco, Acre, Brasil. Ecología Aplicada, v. 11, n. 1, 2012. 
SCORSAFAVA, M. A. et al. Avaliação físico-química da qualidade de água de poços e minas destinada ao consumo humano. Revista do Instituto Adolfo Lutz, v. 69, n. 2, p. 229-232, 2010.

SEMARH. Secretaria do Meio Ambiente e dos Recursos Hídricos. Banco de dados-SEMARH. Disponível em: <http:// servicos.searh.rn.gov.br/semarh/sistemadeinformacoes/consulta/cBaciaDetalhe.asp?CodigoEstadual=01>. Acesso em: 10 abr. 2015.

SILVA, A. G.; SOUZA, L. D. Efeitos antrópicos e sazonais na qualidade da água do Rio do Carmo. Holos, v. 5, p. 122-136, 2013.

SIQUEIRA, G. W.; APRILE, F.; MIGUEIS, A. M. Diagnóstico da qualidade da água do Rio Parauapebas (Pará - Brasil). Acta Amaz. [on-line]. 2012, v. 42, n. 3, p. 413-422. ISSN 0044-5967.

SOUZA, R. S. et al. Água e saúde no município de Igarapé-Açu, Pará. Saúde e Sociedade, v. 25, n. 4, p. 1095-1107, 2016.

STEIN, P. et al. Qualidade das águas do aquífero Barreiras no setor sul de Natal e norte de Parnamirim, Rio Grande do Norte, Brasil. Revista Brasileira de Geociências, v. 42, p. 226-237, 2012.

SZEWCZYK, S. B. O. Processos envolvidos em um derramamento de óleo no mar. In: SEMINÁRIO E WORKSHOP EM ENGENHARIA OCEÂNICA, 6., 2011, Porto Alegre. Anais... Porto Alegre: FURG, 2011. p. 14-24.

TUCCI, C. E. M. Água no meio urbano. In: REBOUÇAS, A. da C. et al. (Org.). Águas doces no Brasil. 3. ed. São Paulo: Escrituras, 2006. p. 399-432.

TUNDISI, J. G. Água no século XXI enfrentando a escassez. São Carlos: RiMa - Instituto Internacional de Ecologia, 2003. $247 p$.

VARGHESE, A. A comparative risk approach to assessing point-of-use water treatment systems in developing countries. In: LINKOV, I.; RAMADAN, A. B. (Ed.). Comparative risk assessment and environmental decision making. New York: Springer, 2004.

VON SPERLING, M. Princípios do Tratamento Biológico de Águas residuárias. 3. ed. Departamento de Engenharia Sanitária e Ambiental/UFMG, Belo Horizonte, MG, 2005.

WRIGHT, J.; GUNDRY, S.; CONROY, R. Household drinking water in developing countries: a systematic review of microbiological contamination between source and point-of-use. Tropical Medicine and International Health, $v$. 9, n. 1, p. 106-117, 2004

ZAN, R. A. et al. Avaliação da qualidade das águas superficiais do Rio Jamari na região da construção de uma PHC no município de Monte Negro - Rondônia, Amazônia Ocidental. Revista Eletrônica em Gestão, Educação e Tecnologia Ambiental, v. 8, n. 8, p. 1876-1888, 2012. 